
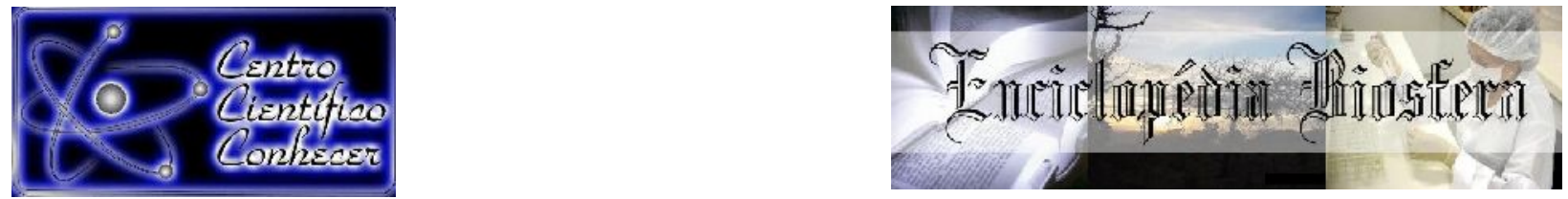

\title{
AVALIAÇÃO ECONÔMICO-FINANCEIRA DA SOJA EM SISTEMA INTEGRADO EM SUCESSÃO AO MILHO NA REGIÃO SUDOESTE DA AMAZÔNIA
}

\author{
Simone Marçal Quintino ${ }^{1}$, Alexandre Martins Abdão dos Passos ${ }^{2}$, Rodrigo da Silva \\ Ribeiro ${ }^{3}$
}
${ }^{1}$ Aluna do Doutorado em Desenvolvimento Regional e Meio Ambiente da Fundação Universidade Federal de Rondônia - UNIR, Porto Velho, RO, Brasil;
${ }^{2}$ Pesquisador da Embrapa Milho e Sorgo, Sete Lagoas, MG, Brasil; Professor do Programa de Pós-Graduação em Desenvolvimento Regional e Meio Ambiente da Fundação Universidade Federal de Rondônia - UNIR, Porto Velho, RO, Brasil; e- mail: alexandre.abdao@embrapa.br
${ }^{3}$ Mestrando em Ciências Ambientais, Universidade Federal de Rondônia - UNIR, Porto Velho, RO, Brasil

\section{Recebido em: 22/09/2018 - Aprovado em: 23/11/2018 - Publicado em: 03/12/2018 DOI: 10.18677/EnciBio 2018B16}

\begin{abstract}
O objetivo dessa pesquisa foi realizar a avaliação econômico-financeira da soja, safra 2017/2018, na região norte do estado de Rondônia, Sudoeste da Amazônia. Foi conduzido um experimento na Unidade de Referência Tecnológica implantada no campo experimental da Embrapa em Porto Velho, Rondônia. O modelo conceitual da área caracteriza-se pela implantação da cultura da soja em plantio direto na safra, milho consorciado com Brachiaria brizantha cultivar Xaraés na segunda safra e criação de gado leiteiro após a soja e milho. Os procedimentos metodológicos consistiram no levantamento dos custos de produção da soja implantada no sistema de integração lavoura-pecuária (iLP). Para a análise econômico utilizou-se o Demonstrativo do Resultado do Exercício, calculando os indicadores de eficiência econômica: margem bruta, margem de contribuição, renda líquida total, renda da família, lucro operacional líquido e lucratividade. Utilizou-se o Demonstrativo de Fluxo de Caixa para análise financeira dos indicadores: Valor Presente Líquido (VPL), Taxa Interna de Retorno (TIR) e Relação Benefício/Custo (B/C), descontado a uma Taxa Mínima de Atratividade de 6,14\% a.a. Realizou-se a Análise de Sensibilidade para verificar os cenários em função das variáveis: preços de comercialização, produtividade e custo de produção tomando como premissa o cenário base utilizado na pesquisa. Os resultados demonstraram um custo de produção de $R \$ 2.971,12 \mathrm{ha}^{-1}$, receita bruta de $R \$ 4.270,64 \mathrm{ha}^{-1}$ e Lucro Operacional Líquido de $\mathrm{R} \$ 1.467,84 \mathrm{ha}^{-1}$, indicando que a atividade foi rentável. O VPL calculado foi de $R \$ 1.287,27$ ha $^{-1}$, TIR de 14,99\% e Relação B/C de 1,48 apontando que a soja cultivada em sistema iLP é economicamente viável nas condições estudadas.
\end{abstract}

RESUMO

PALAVRAS-CHAVE: Análise econômico-financeira. Custo de produção. Sistema de Produção Integrada.

\section{ECONOMIC AND FINANCIAL EVALUATION OF SOYBEAN CROP IN AN INTEGRATED SYSTEM IN THE SOUTHWEST AMAZONIAN REGION}




\begin{abstract}
The aim of this paper was to evaluate the economic and financial balance of a soybean crop, in the season 2017/2018, in the northern region of the state of Rondonia. The experiment was carried out at the Technological Reference Unit located in the experimental field of Embrapa in Porto Velho, Rondonia. A conceptual model of the integrated area was characterized by the soybean crop farming in the season, corn intercropped with Brachiaria brizantha cv Xaraés in the second crop season and dairy cattle exploitation after soybean and corn crops. The methodological procedures consist of a survey of the production costs of the soybean implanted in the integrated system. For the economic analysis, The Statement of income and expenditure (SIE) was used, calculating the economic efficiency indicators: gross margin, contribution margin, total net income, family income, net operating profit and profitability. The Cash Flow Statement was used for financial analysis by the indicators: Net Present Value (NPV), Internal Rate of Return (IRR), Cost Benefit ratio (CBR), discounted at a Minimum Attractiveness Rate of $6,14 \%$ APR. Sensitivity analysis was performed to verify the scenarios according to the variables: soybean prices ( $\mathrm{R} \$$ per bags), productivity (bags per ha) and cost of production ( $\mathrm{R} \$$ per ha) based on the base scenario used in the research. The results showed a cost of production of $R \$ 2,971.12 \mathrm{ha}^{-1}$, gross revenue of $R \$ 4,270.64 \mathrm{ha}$ 1 and Net Operating Income of $\mathrm{R} \$ 1,467.84 \mathrm{ha}^{-1}$, indicating that the activity was profitable. The NPV of $R \$ 1,287.27 \mathrm{ha}^{-1}$, IRR of $14.99 \%$ and CBA Ratio of 1,48 indicates that the soybean crops under integraded cropping systems is economically viable under the studied conditions.
\end{abstract}

KEYWORDS: Economic-financial analysis, Production cost, Integrated Production System.

\title{
INTRODUÇÃO
}

Atualmente, a soja corresponde à cerca de $57 \%$ da área total semeada com grãos no país (CONAB, 2018). A soja produzida no Brasil destaca-se como preeminente atividade agrícola do País, representando relevante papel no crescimento da agricultura e economia de vários estados, tanto na produção de grãos para exportação quanto na destinação de variados usos internos propiciando a consolidação de vastas cadeias agroindustriais (COLOSSI et al., 2016).

A região Norte vem sobressaindo como uma significativa fronteira agrícola, registrando anualmente um crescimento na área cultivada com grãos, principalmente com a cultura da soja. O sucesso da soja é decorrente de variados fatores, tais como o desenvolvimento de pesquisas e tecnologias inovadoras adaptadas à região tropical, novas cultivares de maior potencial produtivo, uso racional de agroquímicos, modos de mecanização adaptados, técnicas de semeadura direta, dentre outras (OLIVEIRA et al., 2016).

Rondônia tem se destacado dentre os estados da região Norte, na produção da soja. Em relação à média nacional evidencia-se um aumento em área de produção de 5,3\% em comparação à safra 2017/2018 (333,4 mil ha) em relação à safra 2016/2017 (296 mil ha). Os dados demonstram que a produção de soja em Rondônia apresentou altos níveis de produtividade média de $3.143 \mathrm{~kg}$ por hectare, dados da safra 2016/17 (CONAB, 2018), superior à média da região Norte de 3.061 $\mathrm{kg}$ por hectare.

A produção da soja em Rondônia concentra-se na região do Cone Sul, e abrange os municípios de Vilhena, Cerejeiras, Corumbiara, Chupinguaia, 
Pimenteiras do Oeste, Cabixi e Colorado do Oeste (GODINHO et al., 2009, SILVA, 2015). Porém, é relevante destacar o crescimento da produção da soja nos últimos anos na região do Vale do Jamari que compreende nove municípios dos quais cinco são produtores da oleaginosa: Ariquemes, Cujubim, Alto Paraíso, Machadinho d' Oeste e Rio Crespo.

O cultivo da soja está consolidado no Cone Sul de Rondônia e sua expansão está ocorrendo nas demais regiões do estado, especialmente em áreas degradadas e de baixos índices produtivos, especialmente pastagens. A expansão dos grãos (soja, milho e arroz) na região se fez em áreas em que a pecuária dominava, com espaço predominante de grandes propriedades (SILVA, 2015).

Uma das grandes preocupações referentes a expansão do cultivo da soja no estado e na região que compreende o Bioma Amazônia é o desflorestamento. Nos estados monitorados pela Moratória da Soja, o aumento da produção se deve essencialmente ao aumento na área plantada. O Relatório divulgado pela ABIOVE (2014) e INPE (2015) referente ao $7^{\circ}$ ano do mapeamento e monitoramento do plantio de soja evidencia que a expansão no bioma Amazônia vem se expandindo essencialmente sobre áreas de pastagens oriundas de desflorestamentos anteriores à Moratória da Soja e que os percentuais de desflorestamentos no bioma vêm diminuindo.

Estima-se que $70 \%$ das áreas de pastagem de Rondônia estão com algum grau de degradação e a soja vem como uma alternativa para a recuperação destes solos, no sistema de integração lavoura-pecuária (iLP). Estudos demonstram que os sistemas de iLP possibilitam a recuperação de áreas degradadas por meio da intensificação do uso da terra, com aumento da eficiência produtiva e sustentabilidade ambiental e econômica (CARAUTA et al., 2018; CARVALHO et al., 2018; COSER et al., 2018; COSTA et al., 2018; OLIVEIRA et al., 2018).

Nestes sistemas, o plantio da soja e outras culturas em consórcio, sucesso e rotação com as áreas de pastagem, permite a recuperação da fertilidade e o aumento da produção das pastagens. Outra vantagem é a possibilidade do cultivo de lavouras forrageiras, após a colheita da soja, seguida o pastejo do gado (CARVALHO et al., 2014, ASSIS, et al., 2015). Agrega-se que o aumento da produção na região Norte do estado dá-se devido à proximidade do porto fluvial em Porto Velho, possibilitando que o custo da saca de soja seja menor quando comparado à região do Cone Sul do estado.

Rondônia tem se destacado no cultivo de grãos de soja nos últimos anos na região Norte, com forte tendência de aumento tanto em produtividade, quantidade produzida e em área de expansão com base nos históricos de produção delineado pela Conab, porém observa-se uma escassez de estudos relacionados à mensuração dos custos de produção e análise dos indicadores econômicofinanceiros da cultura na literatura, principalmente referente ao cultivo em sistemas integrados.

Objetivou-se realizar a avaliação econômico-financeira da soja em sistema integrado sob plantio direto, safra 2017/2018, no norte do estado de Rondônia, região Sudoeste da Amazônia.

\section{MATERIAL E MÉTODOS}

O Experimento composto pelo cultivo da soja (cultivar BRS 7780 IPRO), safra 2017/2018 conduzido no Campo Experimental da Embrapa em Porto Velho, Rondônia, região sudoeste da Amazônia. A área experimental está localizada sob as 
coordenadas geográficas $8^{\circ} 45^{\prime} 43^{\prime \prime}$ Sul, 63 54' 7" Oeste e altitude de 87 metros.

O clima (Köppen) é classificado como tropical úmido do tipo Am, com temperatura média anual de $24,9{ }^{\circ} \mathrm{C}$, precipitação anual entre 2.000 a $2.300 \mathrm{~mm}$ e com estação seca bem definida (junho a setembro) (BASTOS; DINIZ, 1982).

Os solos em que se assentam o experimento são do tipo Latossolo VermelhoAmarelo distrófico, textura argilosa, que abrange cerca de $70 \%$ da área, Argissolo Vermelho Amarelo distrófico e Plintossolo argilúvico distrófico, em menor proporção. O Sistema iLP foi conduzido em sistema plantio direto em uma área de 5 hectares envolvendo o cultivo de soja, milho consorciado com Brachiaria brizantha cultivar Xaraés e pastejo animal na entressafra.

Utilizou-se a metodologia para a apuração dos custos de produção o modelo desenvolvido pelo Instituto de Economia Aplicada - IEA, denominado de custo operacional, descrito por Matsunaga et al. (1976). Para a estruturação e análise dos custos de produção, a metodologia utilizada foi a desenvolvida pela Conab (2010) e Guiducci et al. (2012), com adaptações para a determinação do custeio das atividades produtivas da soja em sistema iLP.

Para a composição dos custos de produção da soja foram utilizados os preços de insumos, operações manuais e mecanizadas vigentes na região norte de Rondônia em outubro de 2017. Os custos de produção envolvem os custos variáveis (insumos, mão de obra, maquinários e outras despesas diretas) fixos (depreciação e manutenção periódica) e custo de oportunidade (remuneração da terra, do custeio e do capital).

Os indicadores de eficiência econômica analisados foram: Receita Operacional Bruta, Renda da Família, Margem de Contribuição, Lucratividade e Ponto de Equilíbrio Econômico, definidos mediante a elaboração do Demonstrativo do Resultado do Exercício - DRE, baseado no período que compreende o cultivo da soja (125 dias) (GUIDUCCI et al. 2012; GITMAN, ZUTTER, 2017).

Considera-se como Receita Operacional Bruta (RB) da atividade por hectare, o produto resultante da quantidade vendida pelo seu respectivo preço, sem abatimentos, sejam eles eventuais descontos ou impostos incidentes sobre o produto. Para o cálculo da RB, utilizou-se o preço de venda da saca de $60 \mathrm{~kg}$ da soja em abril de 2018 no município de Porto Velho.

$R B=P M x V P$

em que:

$\mathrm{RB}=$ renda bruta da atividade $\left(\mathrm{R} \$ \mathrm{ha}^{-1}\right)$;

$\mathrm{PM}=$ produtividade média, quantidade produzida

$\mathrm{VP}=$ valor dos produtos comercializados em $\mathrm{R} \$$

A Renda líquida $(R L)$ é definida como o cálculo da diferença entre a Receita Bruta (RB) e o Custo Total $(\mathrm{CT})$, constitui-se em resíduo que servirá para remunerar o produtor rural.

$R L=R B-C T$

Onde:

RB: Receita Bruta

CT: Custo Total

A Renda da Família (RF) corresponde a renda relativa à mão de obra familiar utilizada na produção, sendo calculada mediante a subtração da Receita Bruta pelo 
Custo Total.

$R F=$ Renda Líquida + Custo de Oportunidade + Trabalho Familiar

A Margem de Contribuição (MC) indica o montante que restou disponível para cobrir os custos fixos. Ou seja, o que restou da receita após a dedução dos custos diretos.

$M C=$ Receitas $-($ Custos e Despesas Variáveis)

A Lucratividade (L) é uma variável que indica qual o rendimento obtido, em relação entre o lucro líquido e a receita total da venda, interpretada como parâmetro geral de eficiência.

$L=\left(\frac{L L}{F V}\right) \times 100$

Onde:

$\mathrm{L}=$ lucratividade $(\%)$;

$\mathrm{LL}=$ Lucro líquido da atividade $\left(\mathrm{R} \$ \mathrm{ha}^{-1}\right)$;

$\mathrm{FV}=$ faturamento com a venda $\left(\mathrm{R} \$ \mathrm{ha}^{-1}\right)$.

Como ferramenta de Análise Financeira, utilizou-se a Demonstração do Fluxo de Caixa Descontado (DFCD) por meio do modelo de planilha eletrônica (MSExcel $^{\circledR}$ ), adaptado conforme modelo proposto por Oliveira e Oliveira (2017) para o período em análise. A partir das informações geradas no fluxo de caixa, procedeu-se os cálculos dos indicadores de viabilidade econômico-financeira com objetivo de subsidiar a tomada de decisão do produtor rural.

Os indicadores de viabilidade econômico-financeira utilizados foram o Valor Presente Líquido (VPL), Taxa Interna de Retorno (TIR), Relação Custo/Benefício (B/C) e Payback (GUIDUCCl et al., 2012; GITMAN, ZUTTER, 2017).

$\mathrm{O}$ Valor Presente Líquido (VPL) equivale à diferença entre o valor presente das receitas e o valor presente dos custos para uma determinada taxa de desconto. O projeto que apresenta o VPL maior que zero é economicamente viável, conforme fórmula abaixo.

$\mathrm{VPL}=\sum_{\mathrm{t}=0}^{\mathrm{n}} \frac{\mathrm{Rt}}{(1+\mathrm{i})^{\mathrm{t}}}-\sum_{\mathrm{t}=0}^{\mathrm{n}} \frac{\mathrm{Ct}}{(1+\mathrm{i})^{\mathrm{t}}}$

Onde:

$\mathrm{Rt}=$ custo total ao final do ano ou período de tempo $\mathrm{t}$;

$\mathrm{Ct}=$ receita total ao final do ano ou período de tem $\mathrm{t}$;

$\mathrm{i}=$ taxa de desconto;

$\mathrm{n}=$ duração do projeto, em anos ou período de tempo.

A Taxa Interna de Retorno (TIR) é a taxa de desconto que busca verificar se a rentabilidade do investimento é superior, inferior ou igual ao custo do capital que será utilizado para financiar o projeto. Considera-se a atividade viável se a TIR for igual ou superior que o custo de oportunidade do capital investido mais a taxa de risco não-diversificáveis, descrita abaixo.

$\sum_{\mathrm{t}=0}^{\mathrm{n}} \frac{\mathrm{R}_{\mathrm{t}}}{(1+\mathrm{I})^{\mathrm{t}}}=\sum_{\mathrm{t}=0}^{\mathrm{n}} \frac{\mathrm{C}_{\mathrm{t}}}{(1+\mathrm{I})^{\mathrm{t}}}$ 
Onde:

$\mathrm{R}_{\mathrm{t}}$ : receita no período $\mathrm{t}$;

$\mathrm{C}_{\mathrm{t}}$ : Custo no período t;

I: investimento inicial;

t: período de tempo analisado;

$\mathrm{n}$ : número de períodos

A Relação Benefício/Custo $(B / C)$ representa a eficiência do sistema de produção, sendo obtida pela relação entre o valor presente dos benefícios e o valor presente dos custos, para uma determinada taxa de desconto, evidenciando a rentabilidade proporcionada pelo investimento.

$B / C=\frac{\sum_{j=0}^{n} R_{I}(1+i)^{-j}}{\sum_{j=0}^{n} C_{I}(1+i)^{-j}}$

Onde:

Rj: Receita no final do ano j

Cj: Custo no Final do ano j

n: duração do projeto, em anos

A Análise de Sensibilidade é uma variação da análise de cenários, em que sua utilidade consiste em assinalar as áreas nas quais o risco de previsão é especialmente grave, tendo como ponto crucial, o congelamento de todas as variáveis, exceto uma, e assim verificar quão sensível é a estimativa de VPL à mudança de valores dessa variável.

Realizou-se cenários em função dos preços de comercialização, produtividade e custo de produção da soja, tomando como premissa o cenário base utilizado na pesquisa. A partir das variáveis em análise (preço, produtividade e custo de produção), consideraram-se três condições de maior favorabilidade, sendo as alterações de $10 \%, 20 \%$ e $30 \%$ a mais, e três de menor favorabilidade de $10 \%, 20 \%$ e $30 \%$ a menos. Os indicadores econômicos analisados foram Renda Líquida, VPL, TIR e Relação Benefício/Custo (B:C).

\section{RESULTADOS E DISCUSSÃO}

O custo total da soja em Sistema iLP referente à safra 2017/2018 foi estimada em $R \$ 2.971,12 \mathrm{ha}^{-1}$, sendo $17,01 \%$ superior aos custos levantados na safra 2016/2017 (PASSOS et al., 2017), com produtividade excedente em $21,88 \%$ quando comparada à colheita anterior. Resultados semelhantes foram observados nas pesquisas de Richetti e Garcia (2017), em análise da viabilidade econômica da soja em Mato Grosso do Sul para a safra 2017/2018, com custo total de produção estimado em $R \$ 2.914,62 \mathrm{ha}^{-1} \mathrm{com}$ a soja $\mathrm{RR}$ e de $\mathrm{R} \$ 2.973,69 \mathrm{com}$ a soja IPRO. O custo de produção da soja transgênica $R R$, em alta tecnologia referente a Safra 2017/2018 estimada pelo Instituto para o Fortalecimento da Agropecuária de Goiás IFAG (2017) foi de $\mathrm{R} \$ 3.720,73 \mathrm{com}$ produtividade de $64,15 \mathrm{sc} \mathrm{ha}^{-1}$. A Figura 01 apresenta a composição dos custos de produção para o cultivo da soja em Sistema iLP na região. 


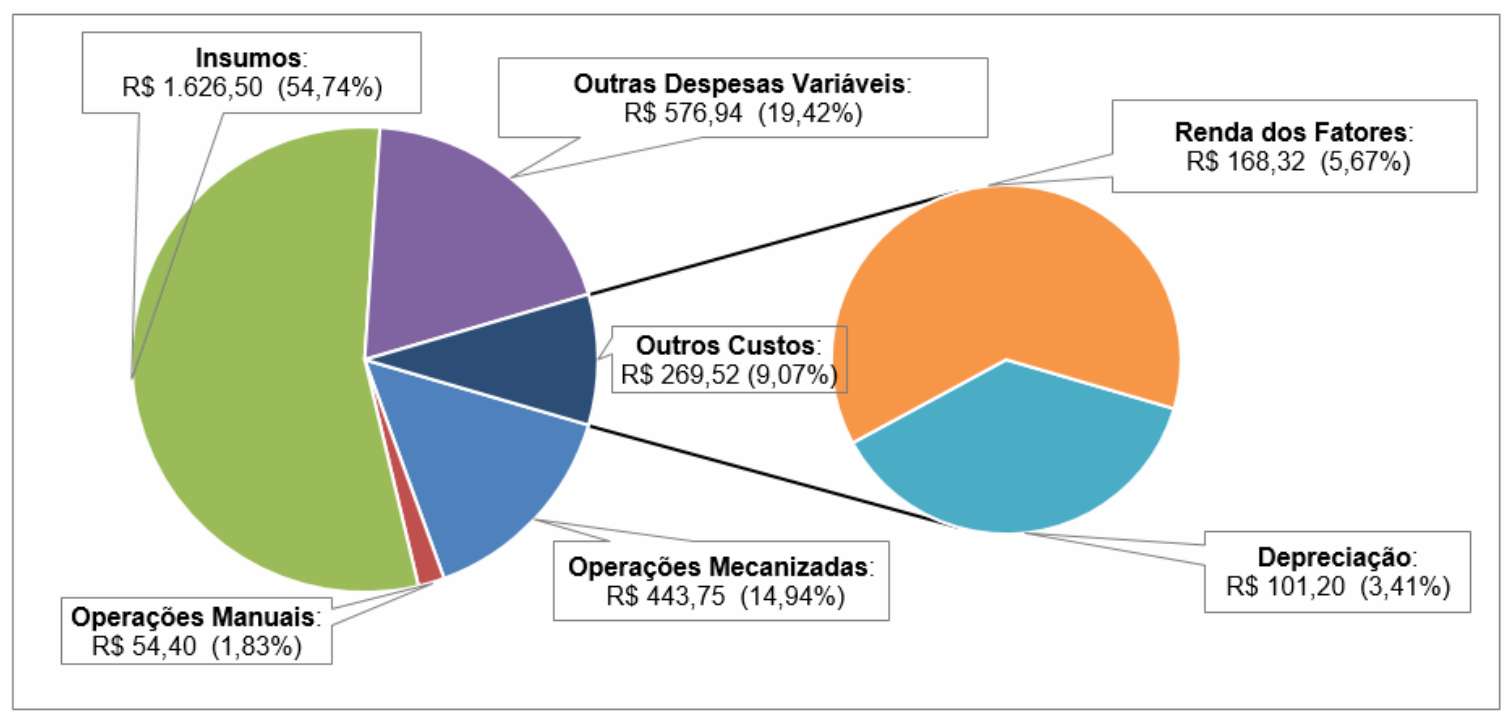

FIGURA 1: Representação absoluta e relativa dos custos de produção soja em Sistema iLP Fonte: os autores (2018)

Os custos variáveis representam $90,93 \%$ do custo total, sendo que os insumos é o componente que mais impacta os custos de produção $(54,74 \%)$. Resultado similar foi evidenciado em estudos de Carvalho et al. (2016), onde os insumos representaram $51,92 \%$ do custo operacional total (COT). Os custos fixos correspondem a $3,41 \%$ e a renda dos fatores, constituída pelo custo de oportunidade (remuneração da terra, capital fixo e de custeio) totaliza $5,67 \%$ do custo total.

A Receita Operacional Bruta (RB) foi calculada em R\$4.270,64 ha ${ }^{-1}$ (Tabela 1) com uma variação percentual superior de $27,41 \%$ em relação à safra anterior (2016/2017). A RB foi baseada no valor médio de venda da saca de $60 \mathrm{~kg}$ na região norte do estado de Rondônia em abril de 2018 por $\mathrm{R} \$ 66,76$ (CONAB, 2018). A Produtividade média do experimento foi mensurada em $3.838 \mathrm{~kg} \mathrm{ha}^{-1}\left(63,97 \mathrm{sc} \mathrm{ha}^{-1}\right)$, acima $17,59 \%$ da média estadual estimada em $3.163 \mathrm{~kg} \mathrm{ha}^{-1}\left(52,72 \mathrm{sc} \mathrm{ha}^{-1}\right) \mathrm{e}$ $22,95 \%$ da média da região Norte, com $2.957 \mathrm{~kg} \mathrm{ha}^{-1}\left(49,28 \mathrm{sc} \mathrm{ha}^{-1}\right)$, considerado como um bom desempenho produtivo (CONAB, 2018). Em relação à média nacional $\left(3.156 \mathrm{~kg} \mathrm{ha}^{-1}\right)$, verifica-se que a produtividade em estudo foi superior em $17,77 \%$, conforme Fig. 02.

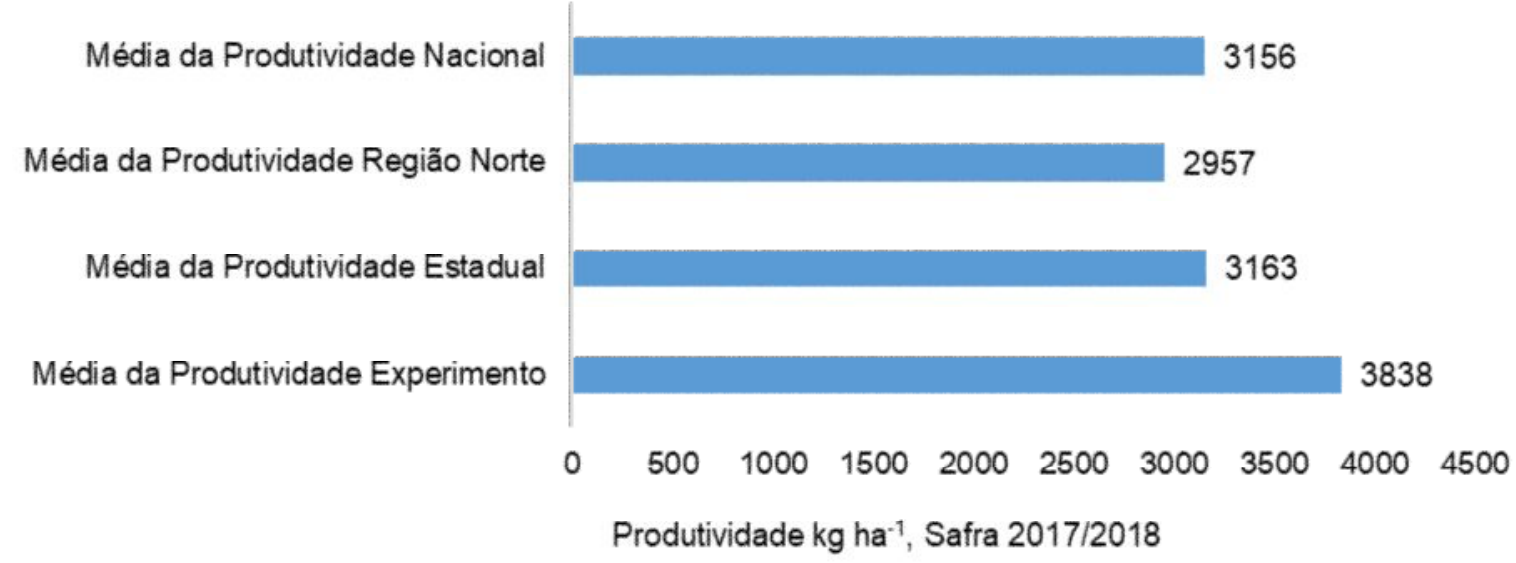

FIGURA 2: Comparativo de produtividade da soja no Sistema iLP com a média produtividade estadual, regional e nacional Safra 2017/2018. Fonte: dados primários e dados Conab (2018) Fonte: os autores (2018) 
A produtividade da soja na safra 2017/2018, região Norte do país foi aquém da safra 2016/2017 (3.061 $\left.\mathrm{kg} \mathrm{ha}^{-1}\right)$. Essa baixa na produtividade da região foi desencadeada pela queda na produtividade da cultivar nos estados de Tocantins, Pará e Amapá. Apenas os estados de Rondônia e Roraima apresentaram aumento de produtividade em relação à safra 2016/2017. É importante ressaltar, que houve aumento na área de produção da soja em todos os estados da região, apesar da queda da produtividade nos estados citados (CONAB, 2018).

A renda líquida Total $(R L)$ foi positiva, atingindo $R \$ 1.229,52 \mathrm{ha}^{-1}$. Este foi o resultado final após a subtração entre o custo total, incluindo os custos de oportunidade e a receita total do período. Os dados indicam que após quitar o custo total, sobrou uma margem de $28,79 \%$.

A Margem de Contribuição (MC) foi positiva com valor de $\mathrm{R} \$ 1.569,04 \mathrm{ha}^{-1}$ demonstrando que a atividade gerou receitas para cobrir todos os custos e despesas fixas. Cada saca de soja contribui individualmente para cobrir os custos fixos e gerar lucro ao produtor rural após as vendas em $\mathrm{R} \$ 24,53$, denominada de Margem de Contribuição Unitária (MCu). O Lucro Operacional Líquido (LOL) apresentou resultado positivo com valor de $R \$ 1.467,84 \mathrm{ha}^{-1}$, indicando que a atividade foi rentável. A Lucratividade (Margem Líquida) foi de $34,37 \%$, demonstrando que para cada unidade de real obtido pela venda da soja, o produtor obterá de lucro $R \$ 0,34$. Cobucci et al. (2007) em pesquisa conduzida no município de Santa Carmem, MT, em Sistema iLP (safra 2006/2007), obtiveram um lucro operacional líquido de $R$ \$ 342,82 , com lucratividade de $24,04 \%$ para a soja $\left(62 \mathrm{sc} \mathrm{ha}^{-1}\right)$ em rotação com arroz, milho e pastagem, sendo 10,33 pontos percentuais abaixo do iLP em estudo.

A Renda da Família (RF) consiste que o produtor rural tem à sua disposição a renda relativa a mão de obra familiar utilizada na produção mais o recurso relativo ao custo de oportunidade (renda dos fatores de produção). Neste estudo, a RF foi de $\mathrm{R} \$ 1.467,84$, valores correspondentes ao Lucro Operacional Líquido. Richetti e Garcia (2017) obtiveram os valores de $\mathrm{R} \$ 818,90$ (soja RR) e $\mathrm{R} \$ 1.045,13$ (soja IPRO) referente a Renda da Família para a Safra 2017/2018 da soja cultivada no estado de Mato Grosso.

TABELA 1: Indicadores de viabilidade econômica da soja na região de Porto Velho Safra 2017/2018

\begin{tabular}{l|c|c}
\hline Indicadores Econômicos & Unidade & Resultados \\
\hline Receita Operacional Bruta (RB) & $\mathrm{R} \$ \mathrm{ha}^{-1}$ & $4.270,64$ \\
\hline Produtividade & $\mathrm{kg} \mathrm{ha}^{-1}$ & 3.838 \\
\hline Renda Líquida Total (RL) & $\mathrm{R} \$ \mathrm{ha}^{-1}$ & $1.229,52$ \\
\hline Margem de Contribuição (MC) & $\mathrm{R} \$ \mathrm{ha}^{-1}$ & $1.569,04$ \\
\hline Margem de Contribuição Unitária (MCu) & $\mathrm{R} \$$ & 24,53 \\
\hline Lucro Operacional Líquido (LOL) & $\mathrm{R} \$ \mathrm{ha}^{-1}$ & $1.467,84$ \\
\hline Lucratividade & $\%$ & 34,37 \\
\hline Renda da Família (RF) & $\mathrm{R} \$ \mathrm{ha}^{-1}$ & $1.467,84$ \\
\hline
\end{tabular}

Fonte: os autores (2018) 
O fluxo de caixa foi elaborado para o período de 04 meses, com as estimativas de entradas e saídas monetárias. Considerando o custo de capital no período e a Taxa Mínima de Atratividade - TMA de 6,14\% a.a., na Tabela 2 verificam-se os resultados dos indicadores econômicos (VPL, TIR e B/C). Baseado nas análises realizadas por esses indicadores econômicos, todos os critérios de avaliação se mostraram economicamente viáveis, demonstrando que a safra foi economicamente viável nas condições estudadas.

TABELA 2: Indicadores de viabilidade econômico-financeira da soja na região de Porto Velho - Safra 2017/2018

\begin{tabular}{l|c|c}
\hline Indicadores Financeiros & Unidade & Resultados \\
\hline Valor Presente Líquido - VPL & $\mathrm{R} \$$ ha $^{-1}$ & $1.287,27$ \\
\hline Taxa Interna de Retorno -TIR & $\%$ & 14,99 \\
\hline Relação Benefício / Custo - B/C & & 1,48 \\
\hline
\end{tabular}

Fonte: os autores (2018)

Conforme Tabela 2 a soja apresentou um VPL maior que zero, evidenciando que a atividade é viável economicamente nas condições analisadas, cujo valor é de $\mathrm{R} \$ 1.287,27 \mathrm{ha}^{-1}$. O VPL representa o lucro do negócio corrigido pela taxa de juros $(6,14 \%$ a. a.), para o período estudado.

A Taxa Interna de Retorno (TIR) proporcionou retorno de 14,99\%, demonstrando que a safra da soja foi financeiramente viável, conforme esse indicador. A TIR foi superior à taxa mínima de atratividade $(6,14 \%$ a.a. $)$, indicando rentabilidade no período em que o capital foi investido nesta atividade, favorecendo assim o investimento no cultivo da soja à aplicação do dinheiro no mercado financeiro a essa TMA.

A Razão Benefício/Custo $(B / C)$ determina a relação entre o valor presente dos benefícios e o valor presente dos custos para uma determinada taxa de juros. Quando a Razão B/C for maior que 1, valida a atividade como economicamente viável. A Razão B/C foi positiva, com resultado de 1,48 demonstrando que para cada $R \$ 1,00$ investido no cultivo da soja, obteve-se $R \$ 1,48$ de receita, ou seja, as receitas superam os custos em $48 \%$. Resultado análogo foi observado em Almeida et al. (2017) com Razão B/C de 1,60 ao analisarem a viabilidade econômica na implantação do cultivo de soja e feijão com sucessão do milho em uma propriedade rural no sudeste de Goiás.

A Tabela 3 apresenta os diferentes cenários para o cultivo da soja, conforme as variações de preço, produtividade e custo de produção, com simulações que permitem a diminuição e o aumento de 10\%, 20\% e 30\% dessas variáveis, demonstrando as mudanças nos indicadores econômico-financeiros Lucro Operacional Líquido, VPL, TIR e Relação B/C. 
TABELA 3: Análise de Sensibilidade da soja cultivada nos Sistema iLP na região norte de Rondônia, considerando variações na produtividade, preço de venda e custo de produção.

\begin{tabular}{|c|c|c|c|c|c|c|c|}
\hline \multirow[t]{2}{*}{ Indicador Econômico } & \multicolumn{3}{|c|}{$\begin{array}{l}\text { Situação Menor } \\
\text { Favorabilidade }\end{array}$} & \multirow{2}{*}{\begin{tabular}{|c|}
$\begin{array}{c}\text { Situação } \\
\text { neutra }\end{array}$ \\
observada \\
\end{tabular}} & \multicolumn{3}{|c|}{$\begin{array}{l}\text { Situação Maior } \\
\text { Favorabilidade }\end{array}$} \\
\hline & $(-) 30 \%$ & $(-) 20 \%$ & $(-) 10 \%$ & & $(+) 10 \%$ & $(+) 20 \%$ & $(+) 30 \%$ \\
\hline \multicolumn{8}{|c|}{ Produtividade (Soja Sistema iLP) } \\
\hline Produtividade (sc ha ${ }^{-1}$ ) & 44,78 & 51,18 & 57,57 & 63,97 & 70,37 & 76,76 & 83,16 \\
\hline Lucro/Prejuízo Operacional $\left(\mathrm{R} \$ \mathrm{ha}^{-1}\right)$ & 254,81 & 659,15 & $1.063,50$ & $1.467,84$ & $1.872,19$ & $2.283,25$ & $2.680,88$ \\
\hline Taxa Interna de Retorno - TIR (\%) & $3,97 \%$ & $8,01 \%$ & $11,66 \%$ & $14,99 \%$ & $18,07 \%$ & $20,97 \%$ & $23,60 \%$ \\
\hline Valor Presente Líquido (VPL) & 167,05 & 540,46 & 913,86 & $1.287,27$ & $1.660,67$ & $2.040,28$ & $2.407,49$ \\
\hline Relação B/C & 1,06 & 1,21 & 1,35 & 1,48 & 1,62 & 1,76 & 1,89 \\
\hline \multicolumn{8}{|c|}{ Preço (Soja Sistema iLP) } \\
\hline Preço (sc ha ${ }^{-1}$ ) & $\mathrm{R} \$ 46,73$ & $\mathrm{R} \$ 53,41$ & $\mathrm{R} \$ 60,08$ & $R \$ 66,76$ & $\mathrm{R} \$ 73,44$ & $\mathrm{R} \$ \mathbf{8 0 , 1 1}$ & $\mathbf{R} \$ \mathbf{8 6 , 7 9}$ \\
\hline Lucro/Prejuízo Operacional $\left(\mathrm{R} \$ \mathrm{ha}^{-1}\right)$ & 205,87 & 626,53 & $1.047,18$ & $1.467,84$ & $1.888,50$ & $2.309,16$ & $2.729,82$ \\
\hline Taxa Interna de Retorno - TIR (\%) & $3,45 \%$ & $7,70 \%$ & $11,52 \%$ & $14,99 \%$ & $18,19 \%$ & $21,15 \%$ & $23,92 \%$ \\
\hline Valor Presente Líquido (VPL) & 121,86 & 510,33 & 898,80 & $1.287,27$ & $1.675,74$ & $2.064,21$ & $2.452,68$ \\
\hline Relação B/C & 1,05 & 1,19 & 1,34 & 1,48 & 1,63 & 1,77 & 1,92 \\
\hline \multicolumn{8}{|c|}{ Custo de Produção (Soja Sistema iLP) } \\
\hline Custo de Produção $\left(\mathbf{R} \$\right.$ ha $\left.^{-1}\right)$ & $1.845,11$ & $2.051,96$ & $2.258,81$ & $2.465,66$ & $2.672,51$ & $2.553,47$ & $2.760,32$ \\
\hline Lucro/Prejuízo Operacional $\left(\mathrm{R} \$ \mathrm{ha}^{-1}\right)$ & $2.259,10$ & $1.995,35$ & $1.731,60$ & $1.467,84$ & $1.204,09$ & 940,34 & 676,58 \\
\hline Taxa Interna de Retorno - TIR (\%) & $27,23 \%$ & $22,56 \%$ & $18,53 \%$ & $14,99 \%$ & $11,85 \%$ & $9,02 \%$ & $6,45 \%$ \\
\hline Valor Presente Líquido (VPL) & $2.066,50$ & $1.806,76$ & $1.547,01$ & $1.287,27$ & $1.027,52$ & 767,78 & 508,04 \\
\hline Relação B/C & 2,10 & 1,85 & 1,65 & 1,48 & 1,35 & 1,24 & 1,15 \\
\hline
\end{tabular}

Fonte: os autores (2018)

Os indicadores econômico-financeiros são muito sensíveis às mudanças na produtividade e preço de venda. Na situação de menor favorabilidade, com redução de $30 \%$ da produtividade, os cenários apresentaram-se viáveis, porém com retração no Lucro Líquido (82,64\%), VPL (87,02\%), TIR (73,51\%) e Relação B/C (28,37\%), quando comparados à situação neutra da variável produtividade. A produtividade mínima da soja é de 44,78 sacas ha ${ }^{-1}$ com preço de comercialização de $\mathrm{R} \$ 62,00$. Quanto ao preço de venda, não poderá ser inferior a $R \$ 46,73$.

No cenário de maior favorabilidade, tanto a variação na produtividade como no preço de venda foram observados resultados satisfatórios de todos os indicadores econômico-financeiros analisados. O acréscimo de 6,4 sacas de soja por hectare proporcionou um aumento de $27,54 \%$ no Lucro Líquido, $20,55 \%$ na TIR, $29 \%$ no VPL e $9,46 \%$ na Relação B/C. Já o aumento máximo, de $30 \%$ na produtividade da soja (19 sc ha-1), resultou em acréscimo do VPL em $87,02 \%$, Lucro Líquido em 82,64\%, TIR em 57,44\% e na Relação B/C de $27,70 \%$.

A diminuição no preço de venda da saca da soja em $30 \%$, acarreta em queda no VPL em $90,53 \%$ ( $\$ \$ 121,86)$ e na TIR em $76,98 \%$. A Relação B/C foi de 1,05 , o que significa que para cada $R \$ 1,00$ investido, o produtor rural obteria de retorno $R \$$ 1,05 , sinalizando que as receitas superaram os custos em apenas $5 \%$.

Porém, todas as variáveis em análise apresentaram resultados satisfatórios quando submetidos ao aumento do preço de vendas em $10 \%, 20 \%$ e $30 \%$. O melhor desempenho refere-se ao aumento de preço de $30 \%$, com variação percentual 
superior do Lucro Líquido Operacional em $85,97 \%$ em relação a situação neutra, e $87,02 \%$ acima do maior VPL $(\mathrm{R} \$ 2.452,68)$.

Observa-se que na situação de melhor favorabilidade, com redução dos custos de produção em $10 \%, 20 \%$ e $30 \%$, todos os cenários apresentaram resultados satisfatórios. A redução dos custos em apenas 10\%, impacta os indicadores econômico-financeiros em Lucro líquido (17,97\%), TIR (23,62\%), VPL $(20,18 \%)$ e Relação B/C (11,49\%). A redução dos custos de produção é uma estratégia que o produtor rural poderá adotar para maximização dos seus lucros e aumento da renda.

\section{CONCLUSÃO}

A produção de soja em sistemas integrados sob plantio direto na região Norte do estado de Rondônia demonstra-se economicamente viável, gerando uma margem de contribuição de $R \$ 1.569,04$ por hectare $(63,26 \%)$, indicando que a prática agropecuária gera receitas para cobrir todos os custos e despesas fixas e ainda lucro ao produtor rural, com uma Renda da Família corresponde a 34,37\% por hectare da Receita Bruta Operacional apontando a rentabilidade do empreendimento.

\section{REFERÊNCIAS}

ABIOVE: Associação Brasileira das Indústrias de Óleos Vegetais. Moratória da Soja mapeamento e monitoramento do plantio de soja no bioma Amazônia - $6^{\circ}$ ano. 2014. Disponível em: http://www.abiove.org.br/site/_FILES/Portugues/03022014160810-baixa.pdf. Acesso em: 29/07/2017

ALMEIDA, I. B. O.; ROSA, D. G.; FERREIRA, R. Z. L.; SILVA, A. C.; ARAÚJO, M. S. Viabilidade econômica da implantação de soja e feijão com sucessão de milho no sudeste de Goiás. Enciclopédia Biosfera, Centro Científico Conhecer. Goiânia, v.14 n.25; p. $2017 . \quad$ Disponível em: http://www.conhecer.org.br/enciclop/2017a/agrar/viabilidade\%20economica.pdf

ASSIS, P. C. R. et al. Atributos físicos do solo em sistemas de integração lavourapecuária-floresta. Revista Brasileira de Engenharia Agrícola e Ambiental, v.19, n.4, p.309-316, 2015. Disponível em: https://www.embrapa.br/busca-depublicacoes/-/publicacao/1010674/atributos-fisicos-do-solo-em-sistemas-deintegracao-lavoura-pecuaria-floresta

BASTOS, T.X.; DINIZ, T.D. de A.S. Avaliação de clima do Estado de Rondônia para desenvolvimento agrícola. Belém: EMBRAPA/CPATU, 1982. 28p. (Boletim de Pesquisa, 44). Disponível em: https://www.embrapa.br/busca-de-publicacoes//publicacao/381150/avaliacao-do-clima-do-estado-de-rondonia-paradesenvolvimento-agricola

CARAUTA, M., LATYNSKIY, E., MÖSSINGER, J., GIL, J., LIBERA, A., HAMPF, A., BERGER, T. Can preferential credit programs speed up the adoption of low-carbon agricultural systems in Mato Grosso, Brazil? Results from bioeconomic microsimulation. Regional Environmental Change, v. 18, n. 1, p. 117-128. 2018. 10.1007/s10113-017-1104-x).<https://doi.org/10.1007/s10113-018-1327-5>. 
doi.org/10.1007/s10113-018-1327-5

CARVALHO, P. C. F. et al. Definições e terminologias para Sistema Integrado de Produção Agropecuária. Revista Ciência Agronômica, v. 45, n. 5 (Especial), p. 1040-1046, $2014 . \quad$ Disponível

http://ccarevista.ufc.br/seer/index.php/ccarevista/article/view/3790

CARVALHO, L. C.; ESPERANCINI, M. S. T.; SANTOS, J. Z.; RIBAS, L. C. Análise comparativa de estimativas de custo de produção e rentabilidade entre sojas rr1 e rr2 pro/bt1. Revista Energia na Agricultura: Botucatu, vol. 31, n.2, p.186-191, $2016 . \quad<h t t p: / / d x . d o i . o r g / 10.17224 / E n e r g A g r i c .2016 v 31 n 2 p 186-191>$. doi.org/10.17224/EnergAgric.2016v31n2p186-191

CARVALHO, P. C. DE F., PETERSON, C. A., NUNES, P. A. DE A., MARTINS, A. P., DE SOUZA FILHO, W., BERTOLAZI, V. T., ANGHINONI, I. Animal production and soil characteristics from integrated crop-livestock systems: toward sustainable intensification. Journal of Animal Science, v. 96, n. 8, p. 3513-3525. 2018 <https://doi.org/10.1093/jas/sky085>. doi.org/10.1093/jas/sky085

CONAB (Brasil). Companhia Nacional de Abastecimento. Acompanhamento da safra brasileira grãos. Monitoramento Agrícola. v. 5 - safra 2017/18 n. 4 - Quarto levantamento. Brasília: janeiro 2018. Disponível em: https://www.conab.gov.br/.../safras/graos/...safra...graos/.../20861_fb79e3ca2b31845 $43 \mathrm{c}$

CONAB (Brasil). Companhia Nacional de Abastecimento. Metodologia de cálculo de custo de produção da CONAB. 2010. Disponível em: http://www.conab.gov.br/conabweb/download/safra/custosproducaometodologia.pdf Acesso em: 12 ago. 2017

COBUCCI, T.; WRUCK, F. J.; KLUTHCOUSKI, J.; MUNIZ, L. C.; MARTHA JÚNIOR, G. B.; CARNEVALLI, R. A.; TEIXEIRA, S. R.; MACHADO, A. A.; TEIXEIRA NETO, M. L. Opções de integração lavoura-pecuária e alguns de seus aspectos econômicos. Informe Agropecuário, v. 28, n. 240, p. 64-79, 2007. Disponível em: https://www.embrapa.br/busca-de-publicacoes/-/publicacao/215859/opcoes-deintegracao-lavoura-pecuaria-e-alguns-de-seus-aspectos-economicos

COLUSSI, J. WEISS, C. R. SOUZA, A. R. L. OLIVEIRA, L. O agronegócio da soja: Uma análise da rentabilidade do cultivo da soja no Brasil. Revista Espacios. v. 37. n.16. 2016.

Disponível

em: http://www.revistaespacios.com/a16v37n16/16371623.html.

COSER, T. R., DE FIGUEIREDO, C. C., JOVANOVIC, B., MOREIRA, T. N., LEITE, G. G., CABRAL FILHO, S. L. S., MARCHÃO, R. L. Short-term buildup of carbon from a low-productivity pastureland to an agrisilviculture system in the Brazilian savannah. Agricultural Systems, $\mathrm{pp}$. 184-195. 2018. 
<https://doi.org/10.1016/j.agsy.2018.01.030>. doi.org/10.1016/j.agsy.2018.01.030

COSTA, M. P., SCHOENEBOOM, J. C., OLIVEIRA, S. A., VIÑAS, R. S., \& DE MEDEIROS, G. A. A socio-eco-efficiency analysis of integrated and non-integrated crop-livestock-forestry systems in the Brazilian Cerrado based on LCA. Journal of

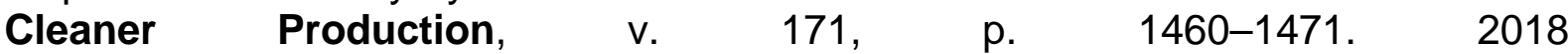
<https://doi.org/10.1016/j.jclepro.2017.10.063>. doi.org/10.1016/j.jclepro.2017.10.063

GITMAN, L. J.; ZUTTER, C. J. Princípios de Administração Financeira. 14 ed., São Paulo: Editora Pearson, 2017, 848p.

GODINHO, V. P. C. et al. Estimativa do custo de produção de soja, em plantio direto, em Vilhena - safra 2008/2009. Comunicado Técnico, EMBRAPA: Junho, Porto Velho: 2009. Disponível em: https://www.embrapa.br/busca-de-publicacoes//publicacao/710950/estimativa-do-custo-de-producao-de-soja-em-plantio-direto-emvilhena-ro-safra-20082009

GUIDUCCI, R. do C. N.; ALVES, E. R. de A.; LIMA FILHO, J. R.; MOTA, M. M. Aspectos metodológicos da análise de viabilidade econômica de sistemas de produção. In: GUIDUCCI, R. do C. N.; LIMA FILHO, J. R.; MOTA, M. M. (Ed.). Viabilidade econômica de sistemas de produção agropecuários: metodologia e estudos de caso. Brasília: Embrapa, 2012. p. 17-78. Disponível em: https://www.embrapa.br/busca-de-publicacoes/-/publicacao/959077/aspectosmetodologicos-da-analise-de-viabilidade-economica-de-sistemas-de-producao

INPE: Instituto Nacional de Pesquisas Espaciais. Moratória da Soja mapeamento e monitoramento do plantio de soja no bioma Amazônia - $6^{\circ}$ ano. 2015. Disponível em www.obt.inpe.br/prodes. Acesso: 19/07/2015.

IFAG: Instituto para o Fortalecimento da Agropecuária de Goiás (2017). Custo de Produção. 2017. Disponível em: http://ifag.org.br/custos-de-producao

MATSUNAGA, M., et al. Metodologia de custo de produção utilizado pelo IEA. Agricultura em São Paulo, 23(1):123-139. 1976. Disponível em: http://www.iea.sp.gov.br/out/verTexto.php?codTexto=11566

OLIVEIRA, P. A.; CERVI, R. G.; RODRIGUES, S. A.; CAMPOS, B. C. Análise dos custos de produção para o cultivo da soja em cenários distintos de produtividade $\mathrm{e}$ preço no interior paulista. Revista do Agronegócio - Reagro, Jales, v. 5, n. esp., p. 58 - 66, dez. 2016. Disponível em: http://www.fatecjales.edu.br/sintagro/images/anais/tematica5/analise-dos-custos-deproducao-para-o-cultivo-da-soja-em-cenarios-distintos-de-produtividade-e-preco-nointerior-paulista.pdf

OLIVEIRA, D. L.; OLIVEIRA, G. D. Contabilidade Rural: uma abordagem do 
agronegócio dento da porteira com exercícios práticos e material de apoio ao professor - de acordo com o CPC 29 (IAS 41). 3르 ed. Curitiba: Juruá Editora, 2017

OLIVEIRA, J. DE M., MADARI, B. E., CARVALHO, M. T. DE M., ASSIS, P. C. R., SILVEIRA, A. L. R., DE LELES LIMA, M., MACHADO, P. L. O. de A. Integrated farming systems for improving soil carbon balance in the southern Amazon of Brazil. Regional Environmental Change, v. 18, n. 1, p. 105-116. 2018 <https://doi.org/10.1007/s10113-017-1146-0>. doi.org/10.1007/s10113-017-1146-0

PASSOS, A. M. A.; QUINTINO, S. M.; RIBEIRO, R. S. Custo de Produção Estimado para a Cultura da Soja em Sucessão ao Milho em Sistema ILP, na Região de Porto Velho, Rondônia, Safra 2016/17. Embrapa Milho e Sorgo. Comunicado Técnico no 234. Sete Lagoas: 2017. Disponível em: https://www.embrapa.br/busca-depublicacoes/-/publicacao/1086291/custo-de-producao-estimado-para-a-cultura-dasoja-em-sucessao-ao-milho-em-sistema-ilp-na-regiao-de-porto-velho-rondonia-safra201617

RICHETTI, A.; GARCIA, R. A. Viabilidade Econômica da Cultura da Soja para a Safra 2017/2018, em Mato Grosso do Sul. Comunicado Técnico n. 228. ISSN 16790472. Embrapa Agropecuária Oeste. Dourados, MS: Agosto, 2017. Disponível em: https://www.embrapa.br/busca-de-publicacoes/-/publicacao/1074401/viabilidadeeconomica-da-cultura-da-soja-para-a-safra-20172018-em-mato-grosso-do-sul

SILVA, R. G. C. Amazônia globalizada: da fronteira agrícola ao território do agronegócio - o exemplo de Rondônia. Confins [Online] Revista Franco-Brasileira de Geografia, ํo 23, 2015. Disponível em: http://confins.revues.org/9949. Acesso em 30/07/2018 